\title{
Traumatic left ventricular aneurysm in an 8-year-old child
}

\author{
DAVID SMITH, DUNCAN WALKER, * MARVIN STURRIDGE \\ From the Departments of Paediatrics and Cardiothoracic Surgery, The Middlesex Hospital, London
}

SUMMARY An asymptomatic 8-year-old boy was found to have a left ventricular aneurysm and a ventricular septal defect 14 months after a road traffic accident. At operation a large, thin-walled, clot-filled aneurysm was removed and the septal defect repaired.

\section{Case report}

In July 1976, an 8-year-old West Indian boy was struck by a car while chasing a football across a road. On arrival at a nearby hospital he was found to be unconscious with lacerations on the left forehead, bruising of the anterior chest wall and abdomen, and fractures of the left radius and ulna and both femoral shafts.

He soon regained consciousness but remained drowsy. Clinical examination disclosed no abnormality of the heart or lungs and a chest $x$-ray was normal. Over the next 24 hours the level of consciousness returned to normal, but stable reduction of the right femoral fracture could not be obtained and a pin and plate were inserted. Recovery thereafter was straightforward and a chest $x$-ray just before his discharge was normal. The boy was followed up by the orthopaedic surgeon and readmitted in August 1977 to have the plate removed.

On admission he appeared well. He had been extremely active over the preceding six months, with no exercise intolerance. On admission, however, abnormal signs were found in his heart and he was referred for a cardiological opinion.

On examination he appeared healthy and well grown. There was no evidence of cyanosis or clubbing. The peripheral pulses were all of normal volume. The heart rate was 92 per minute. The heart sounds were normal but a grade $3 / 6$ pansystolic murmur was audible maximally in the fourth intercostal space at the left sternal border and a grade 2/4 mid-diastolic murmur, heard at the same site, was conducted to the apex. Chest $x$-ray (Fig. 1) showed a localised convexity on the

$\star$ Present address: Department of Cardiothoracic Surgery, Killingbeck Hospital, Leeds. anterolateral aspect of the cardiac silhouette, visible in both the posteroanterior and left lateral projections. The electrocardiogram showed sinus rhythm with a normal $P$ wave and vector; the mean QRS axis in the frontal plane was $+90^{\circ}$. The ventricular forces were normal for age, with no evidence of ischaemia or left ventricular strain.

He was admitted to The Middlesex Hospital where cardiac catheterisation was performed. The right ventricular pressure was normal at $25 / 4$ $\mathrm{mmHg}$, with a pulmonary arterial pressure of $22 / 15$ $\mathrm{mmHg}$. Left sided pressures were all normal with an arterial pressure of $110 / 80 \mathrm{mmHg}$.

Oxygen saturation rose from 77 per cent in the inflow portion of the right ventricle to 80 per cent in the outflow tract, and the $\mathrm{QP} / \mathrm{QS}$ ratio was 1.3 (Fick). The catheter crossed the interventricular septum and entered a diverticulum of the left ventricle. A cineangiogram in the left anterior oblique position showed a saccular aneurysm of the left ventricle. A retrograde arterial catheter was inserted into the left ventricle and cineangiography performed in the right anterior oblique position (Fig. 2). This showed that the aneurysm arose from the anterolateral aspect of the left ventricle. The sac had a well defined neck and its wall moved paradoxically. Further cineventriculography in the left anterior oblique position showed a small high ventricular septal defect with a left-to-right shunt. At operation (December 1977) there was an aneurysmal bulge on the anterolateral wall of the left ventricle in the line of the anterior descending coronary artery and extending downwards from the atrioventricular groove, with a thin-walled central dome. The aneurysm was incised and the interior of the ventricle inspected. The inner surface of the aneurysm had organised thrombus attached to it 


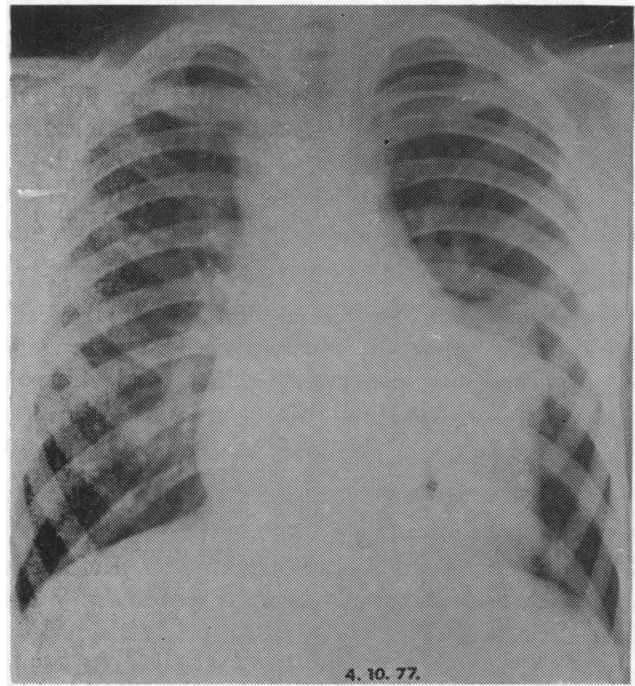

Fig. 1 Chest $\mathrm{x}$-ray, posteroanterior and lateral.

and this was removed. A scar was seen in the adjacent interventricular septum and a small defect $3 \mathrm{~mm}$ in diameter was found. This was sutured. The aneurysm was excised and the left ventricular wall repaired.

The child's recovery was uneventful and he was

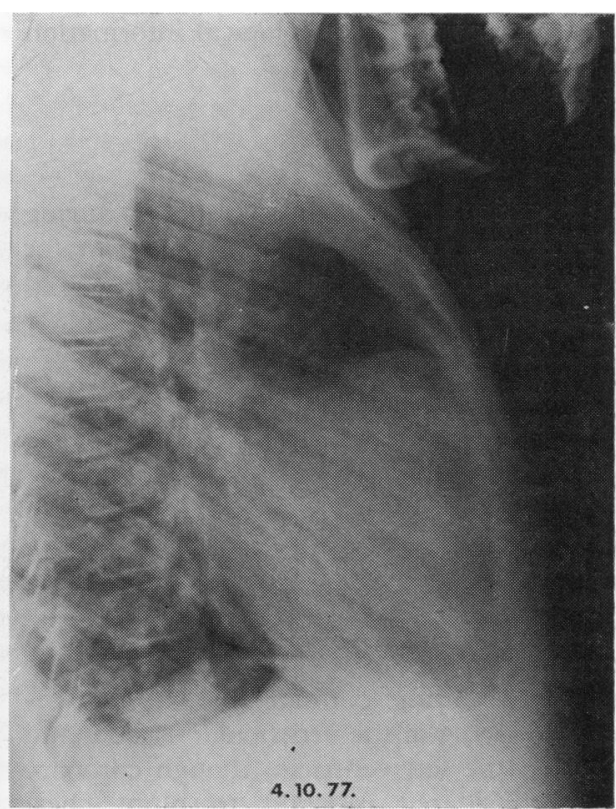

4. 10.77 . discharged on the fifteenth postoperative day. $\mathrm{He}$ made excellent progress at home and was allowed to return to school, but two months after the operation he suddenly collapsed and was found to be dead on arrival at hospital. A coroner's necropsy was performed but failed to show the cause of death.
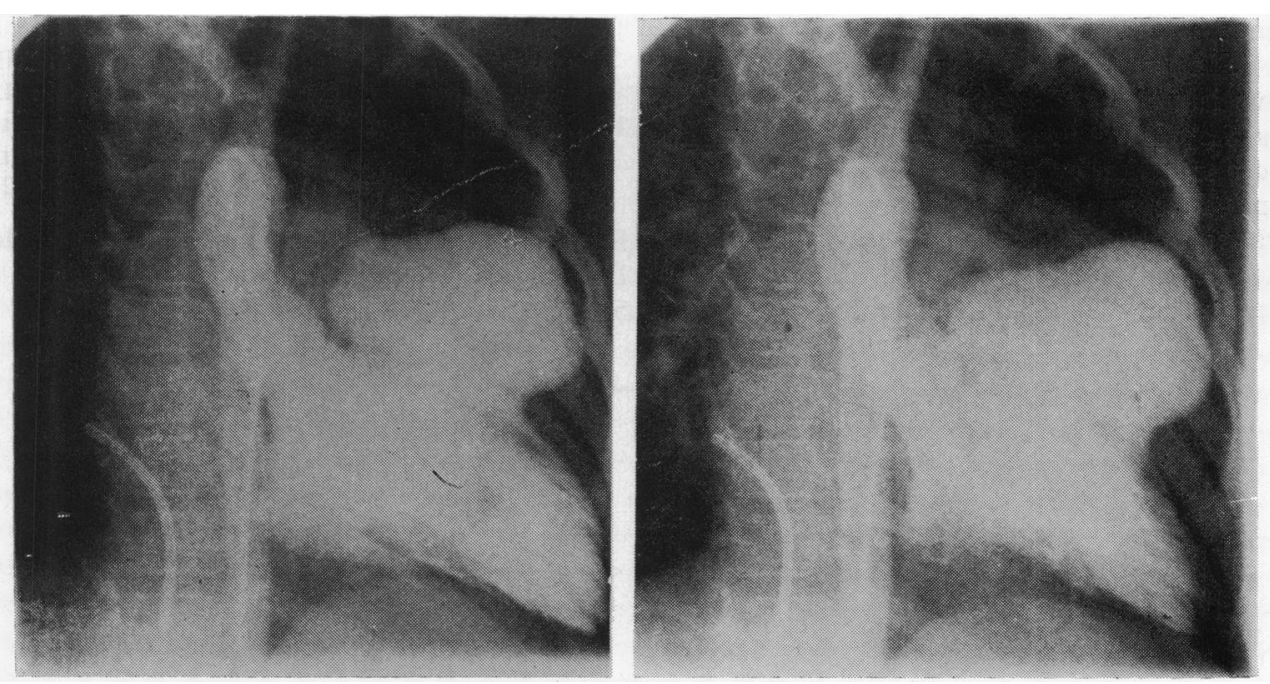

Fig. 2 Left ventricular injection in right anterior oblique position, diastolic (left) and systolic frames. 
No further pathological or histological information was obtained.

\section{Discussion}

Traumatic ventricular septal defects occur during childhood. ${ }^{1}$ They have followed high speed motor accidents, ${ }^{2}$ and are also seen as part of the battered baby syndrome. ${ }^{3}$

Left ventricular aneurysms in childhood have also been described which may be congenital, ${ }^{4}$ secondary to anomalous origin of the left coronary artery, ${ }^{5}$ or to rubella myocarditis. ${ }^{6}$ Calcific apical aneurysms are known to occur almost exclusively in Africans. ${ }^{7}$ Traumatic aneurysms occurring at any age as sequelae to blunt chest trauma are rare $^{8}$ and especially so in children, in whom few have been diagnosed before death. ${ }^{9}$

In our patient it seems possible that damage to the anterior descending coronary artery was responsible for scarring of the ventricular septum and anterior wall of the left ventricle, though coronary arteries are considered resistant to blunt chest trauma. ${ }^{10}$ An alternative explanation is direct contusion to the myocardium followed by thinning of scar tissue, dilatation, and aneurysm formation.

Despite this severe cardiac injury, the boy remained totally asymptomatic, and the abnormality was discovered fortuitously. The source of his diastolic murmur was presumed to be the passage of blood from the aneurysmal sac into the ventricular cavity proper and not increased flow across the mitral valve, for the shunt was too small.

Previous authors ${ }^{11-13}$ have described the symptoms produced by such lesions and the danger of death from rupture or embolism if surgery is not performed. The success of surgery in traumatic aneurysms is supported by the published reports ${ }^{8}$ and it is therefore particularly disappointing that this child should have died suddenly, soon after the operation. This suggests a rhythm disturbance, and perhaps indicates a need for caution in the rehabilitation particularly of active children after open heart surgery for traumatic injury.

\section{References}

1 Moraes CR, Victor EG, Artuda MB, et al. Ventricular septal defect following nonpenetrating trauma. Case report and review of the surgical literature. Angiology 1973; 24: 222-9.

2 Goggin MJ, Thompson FD, Jackson JW. Deceleration trauma to the heart and great vessels after roadtraffic accidents. Br Med F 1970; ii: 767-9.

3 Rees A, Symons J, Joseph M, Lincoln C. Ventricular septal defect in a battered child. $B r \operatorname{Med} \mathcal{F} 1975$; i: 20-21.

4 Paronetto F, Strauss L. Aneurysm of the left ventricle due to congenital muscle defect in an infant. Report of a case with discussion of pathogenesis of associated endocardial fibroelastosis. Am $\mathcal{f}$ Cardiol 1963; 12: 721-9.

5 Bland EF, White PD, Garland J. Congenital anomalies of the coronary arteries: report of an unusual case associated with cardiac hypertrophy. Am Heart f 1933; 8: 787-801.

6 Van der Horst RL, Gotsman MS. Left ventricular aneurysm in rubella heart disease. $\mathrm{Am} \mathcal{F}$ Dis Child 1970; 120: 248-51.

7 Pocock WA, Cockshott WP, Ball PJA, Steiner RE. Left ventricular aneurysms of uncertain aetiology. Br Heart F 1965; 27: 184-92.

8 Berkoff HA, Rowe GG, Crummy AB, Kahn DR. Asymptomatic left ventricular aneurysm: a sequela of blunt chest trauma. Circulation 1977; 55: 545-8.

9 Killen DA, Gobbel WG Jr, France R, Vix VA. Post-traumatic aneurysm of the left ventricle. Circulation 1969; 39: 101-8.

10 Parmley LF, Manion WC, Mattingly TW. Nonpenetrating traumatic injury of the heart. Circulation 1958; 18: 371-96.

11 Hawkes SZ. Traumatic rupture of the heart and intrapericardial structures. Am f Surg 1935; 27: 503-7.

12 Glancy DL, Yarnell P, Roberts WC. Traumatic left ventricular aneurysm. Cardiac thrombosis following aneurysmectomy. Am f Cardiol 1967; 20: 428-33.

13 Singh R, Nolan SP, Schrank JP. Traumatic left ventricular aneurysm. Two cases with normal coronary angiograms. $\mathcal{F} A M A 1975 ; 234: 412-4$.

Requests for reprints to Dr D R S Smith, Children's Department, Dryburn Hospital, Durham DH1 5TW. 